\title{
Complete Immunization against Trypanosoma cruzi Verified in Individual Mice by Complement-Mediated Lysis
}

\author{
Laura E Gómez*, Julio R Nasser, Miguel A Basombrío
}

Laboratorio de Patología Experimental, Facultad de Ciencias de la Salud, Universidad Nacional de Salta, Calle Buenos Aires 177, 4400 Salta, Argentina

Experimental systems to assay immunity against Trypanosoma cruzi usually demonstrate partial resistance without excluding the establishment of sub-patent infections in protected animals. To test whether Swiss mice immunized with attenuated parasites might develop complete resistance against virulent $\mathrm{T}$. cruzi, experiments were performed involving challenge with low numbers of parasites, enhancement of local inflammation and the combination of natural and acquired resistance. Absence of infection was established after repeated negative parasitological tests (including xenodiagnosis and hemoculture), and lack of lytic antibody was tested by complement mediated lysis. Immunization with $10^{7}$ attenuated epimastigotes conferred protection against the development of high levels of parasitemia after challenge with Tulahuen strain, but was unable to reduce the number of infected animals. However, when a strong, delayed-type hypersensitivity reaction was triggered at the site of infection by injecting a mixture of virulent and attenuated T. cruzi, a significant proportion of immunized animals remained totally free of virulent infection. The same result was obtained when the immunization experiment was performed in four month old Swiss mice, displaying a relatively high natural resistance and challenged with wild, vector-borne parasites. These experiments demonstrate that complete resistance against $\mathrm{T}$. cruzi can be obtained in a significant proportion of animals, under conditions which replicate natural, vector delivered infection by the parasite.

Key words: Trypanosoma cruzi - lytic antibodies - immunological resistance

Chagas' disease, caused by Trypanosoma cruzi, presents three main clinical forms: acute, inapparent and chronic. The parasite can be detected in blood during the acute stage, but in the remaining stages, parasitemia is usually low and diagnosis is established by detecting specific antibodies using various techniques. Spontaneous cure with negative serology has been observed, but only on rare occasions (Brener \& Plessman Camargo 1982, WHO 1991).

Immunologic protection against experimental T. cruzi infection has been achieved with several experimental vaccines, (for review see Kierszenbaum 1989) including, more recently, parasite synthetic peptide (Bua et al. 1991). As a result of vaccination, significant reductions have been obtained in parasitemia level (Andrews et al. 1985, McHardy \& Elphick 1980), pathology (Kierszenbaum 1989) and transmission to vectors (Basombrío et al. 1993). Stronger effects of protection would be the achievement of "sterile im-

This work was supported by UNDP/World Bank/WHO Special Programme for Research and Training in Tropical Diseases, CONICET and Consejo de Investigación de la UNSa.

*Corresponding author

Received 2 May 1995

Accepted 29 August 1995 munity" after immunization with non viable vaccines or, at least, "complete immunity" against a second infection, which we define here as the absence of any positive parasitological test or serological evidence of infection after an infective challenge, in individual mice (not groups) preimmunized with attenuated vaccines.

The success of experimental vaccination against $T$. cruzi becomes highly questionable when protection is verified with highly sensitive methods (Brener \& Plessman Camargo 1982, Kierszenbaum 1989). Mc Hardy and Elphick (1980) demonstrated that infection with small doses, such as might be introduced after a triatomid bite ( 2 to 100 parasites) infect vaccinated and control mice equally well, a fact confirmed in our laboratory (Basombrío et al. 1989).

Among the humoral responses to T. cruzi infection, antibodies that can lyse bloodstream trypomastigotes in the presence of complement are generated (Krettli \& Brener 1982). These lytic antibodies can be detected with the complement mediated lysis (CML) technique. Lytic antibodies are important immunologic effectors, associated with active infection and resistance against this parasite (Krettli \& Brener 1982). The absence of lytic antibodies is considered to be indicative of cure, in spite of positive findings with other, so called, conventional serological tests (Krettli et al. 
1982, Galvão et al. 1993).

Lytic antibodies are not equally effective in killing all strains or clones of T. cruzi (Krettli \& Brener 1976, Murfin \& Kuhn 1988), and CML should not be, therefore, useful to exclude infection by such parasites. For example in our laboratory, CML does not exclude attenuated infections by a low virulence strain (TCC). However, this technique is, in our hands, a good tool to exclude infection with virulent $T$. cruzi of the Tulahuen strain or local wild isolates.

In this work, we studied whether complete immunity against Tulahuen and wild T. cruzi parasites, can be induced by prior injection of the TCC strain. To obtain convincing evidence for the lack of residual infection by the virulent challenge, after exhausting the parasitological determinations, we used the CML technique. This study allowed us to identify three possible factors determining complete immunity in a discrete proportion of animals: a high level of natural host resistance, the vectorial origin of infecting parasites and the development of a strong delayed type hypersensitivity reaction at the site of infection.

\section{MATERIALS AND METHODS}

Animals - All experiments were performed using outbred Swiss mice raised at our breeding facility. Both sexes were used, but were not mixed in any given experiment. Animals were 30 to 60 days old at the begining of the experiments.

Parasites - Culture forms of T. cruzi (TCC) were used as sensitizing antigen and as triggering antigen in delayed type hypersensitivity reactions. The TCC subline of Tulahuen T. cruzi underwent attenuation in virulence and pathogenicity after more than 17 years of continuous passage in culture (Basombrío et al. 1982). Cultures were grown in Liver Infusion Tryptose (LIT) medium supplemented with $10 \%$ fetal bovine serum (GENsa) decomplemented at $68^{\circ} \mathrm{C}$ for $60 \mathrm{~min}$, $20 \mu \mathrm{g}$ hemin (Sigma), $100 \mathrm{IU}$ of penicillin and $100 \mu \mathrm{g}$ streptomycin per $\mathrm{ml}$.

To challenge the mice we used either nonattenuated Tulahuen strain or wild isolates of $T$. cruzi. The former strain was maintained by mouse to mouse passages of infected blood. The wild isolates were obtained from Triatoma infestans bugs colonizing a guinea pig yard (Basombrío et al. 1987). The feces of infected bugs were diluted in LIT medium as to obtain the desired concentration of metacyclic trypomastigotes in the inoculum. Contaminating epimastigotes were not counted.

Delayed type hypersensitivity reactions - Mice were sensitized by injection of $30 \mu \mathrm{l}$ of TCC suspension in saline (10 $70^{7}$ TC epimastigotes), into the left hind footpad. One week later, a triggering inoculum of the same size was given in the right hind footpad. After 20 min and 4, 18, 24, 48, and $72 \mathrm{hr}$, swelling of the right hind footpad was measured with a caliper. In selected cases, animals were killed $24 \mathrm{hr}$ post-challenge and the right hind footpads were fixed in $10 \%$ formalin. Decalcified and paraffin-embedded sections were stained with hematoxylin-eosin and studied histopathologically.

Fresh blood mounts - $10 \mu \mathrm{l}$ of tail vein blood was collected into heparinized capillary tubes and placed between a microscope slide and coverslip, counting the parasites in 100 microscopic fields $(480 \mathrm{x})$.

Microhematocrit - Three capillary tubes, each filled with $50 \mu$ of blood were centrifuged at $9500 \mathrm{x}$ g for $2 \mathrm{~min}$ and cut at the parasite-enriched leukocyte interphase, which was then examined microscopically.

Xenodiagnosis - Ten 2nd or 3rd instar $T$. infestans, fasted for a month were allowed to feed on each penthotal-anesthesized mouse for $15 \mathrm{~min}$ in the dark. Thirty and 60 days later, a pool of bug feces diluted in $10 \mu \mathrm{l}$ of LIT medium was examined microscopically for the presence of parasites.

Hemoculture - Blood $(0.2 \mathrm{ml})$ was collected with sterile heparinized Pasteur pipettes from the tail tip of mice, seeded into $75 \mathrm{~mm}$ of length and $9 \mathrm{~mm}$ of diameter glass tubes containing $1.8 \mathrm{ml}$ of complete LIT medium and incubated at $28^{\circ} \mathrm{C}$.

After 15, 30, 45 and 60 days, the presence of motile parasites was established using an inverted microscope.

CML technique - Tulahuen bloodstream trypomastigotes were obtained from highly parasitemic Balb/c mice which had been immunosuppressed with a dose of $350 \mathrm{mg} / \mathrm{kg}$ cyclophosphamide (LABINCA S.A., Buenos Aires) $24 \mathrm{hr}$ before infection. After isolating the parasites by differential centrifugation at $150 \mathrm{x}$ g for $20 \mathrm{~min}$ followed by an incubation at $37^{\circ} \mathrm{C}$ during $4 \mathrm{hr}$; they were washed three times at $3000 \mathrm{xg}$ for 6 min, in minimum essential medium Eagle plus $10 \%$ inactivated fetal bovine serum (MEM-FBS) and incubated for $30 \mathrm{~min}$ in human normal fresh serum. Test sera decomplemented at $56^{\circ} \mathrm{C}$ for 30 min, were diluted 1:2 in MEM-FBS, mixed with a suspension of $5 \times 10^{6} / \mathrm{ml}$ washed trypomastigotes and incubated for $30 \mathrm{~min}$ at $37^{\circ} \mathrm{C}$. The samples were then separated into two $50 \mu \mathrm{l}$ aliquots (A and B) and kept in an ice bath until $50 \mu$ of human normal fresh serum was added to aliquot $\mathrm{A}$ and $50 \mu \mathrm{l}$ of human heat inactivated serum to aliquot $\mathrm{B}$. After mixing and incubating at $37^{\circ} \mathrm{C}$ for $60 \mathrm{~min}$, the samples were transferred to an ice bath until motile parasites were counted microscopically using a hemocytometer to calculate the 
percent of lysis. More than $80 \%$ lysis was considered a positive result, indicating infection by Tulahuen or wild T. cruzi. Less than $20 \%$ lysis was taken as negative result. Only 1 of 132 animals fell between 20 and $80 \%$ lysis and was considered positive.

Statistical analysis - Delayed type hypersensitivity results were evaluated with Mann-Whitney "U" test and rates of infection with Fisher's exact test.

\section{RESULTS}

Correlation between lytic antibodies detection by CML and parasitological tests detecting low T. cruzi infection - Several experiments were performed, where CML and parasitological tests (fresh blood mount, microhematocrit and xenodiagnosis or hemoculture) were applied to mice infected with virulent $T$. cruzi. Each of these methods was applied several times to each mouse, during the acute phase of infection. Most of these animals (132/143) had been injected with threshold infective doses 10 to 100 parasites. The load of infection obtained was classified in four grades, according to the sensitivity of the diagnostic method necessary for detection (Table I). The lack of CML closely correlated ( $\left.\mathrm{p}<10^{-11}\right)$ with negative parasitological tests. CML was the most sensitive method to detect low grade infections.

Failure to induce complete resistance against low doses of $\mathrm{T}$. cruzi - An immunization-challenge experiment was performed where 45 day-old mice were primed with $10^{7} \mathrm{TCC}$ in the left hind footpad and challenged with virulent Tulahuen trypomastigotes in the right hind footpad. This challenge dose was adjusted to a threshold of infectivity (10 Tulahuen trypomastigotes) that would infect about half of the control mice. The average levels of parasitemia in the immunized group were

\section{TABLE I}

Comparison of different methods to detect residual infection by Trypanosoma cruzi

\begin{tabular}{|c|c|c|c|c|c|}
\hline \multirow[t]{2}{*}{ Grade $^{a}$} & \multicolumn{3}{|c|}{$\begin{array}{c}\text { Result of } \\
\text { parasitological test }\end{array}$} & \multirow[t]{2}{*}{$\mathrm{CML}$ total $^{b}$} & \multirow[t]{2}{*}{$\%(+)$} \\
\hline & FBM & $\mathrm{MH}$ & $\mathrm{X} / \mathrm{H}$ & & \\
\hline I & + & + & + & $33 / 34$ & 97 \\
\hline II & - & + & + & $5 / 5$ & 100 \\
\hline III & - & - & + & $7 / 7$ & 100 \\
\hline IV & - & - & - & $2 / 97$ & 2 \\
\hline
\end{tabular}

$a$ : grades I, II, III and IV, indicate different degrees of parasitemia. $b$ : no. of mice with lytic antibodies/total mice studied. Abreviations: FBM = fresh blood mount; $\mathrm{MH}=$ microhematocrit; $\mathrm{X}=$ xenodiagnosis; $\mathrm{H}=$ hemoculture; $\mathrm{CML}=$ complement mediated lysis. much lower than in the controls (Fig. 1). However, an exhaustive search for parasites in eight fresh blood mounts (day 15 to 49) and one xenodiagnosis (day 57), revealed that such resistance was not complete, since the low challenge doses had infected the same proportion of immunized and control mice.

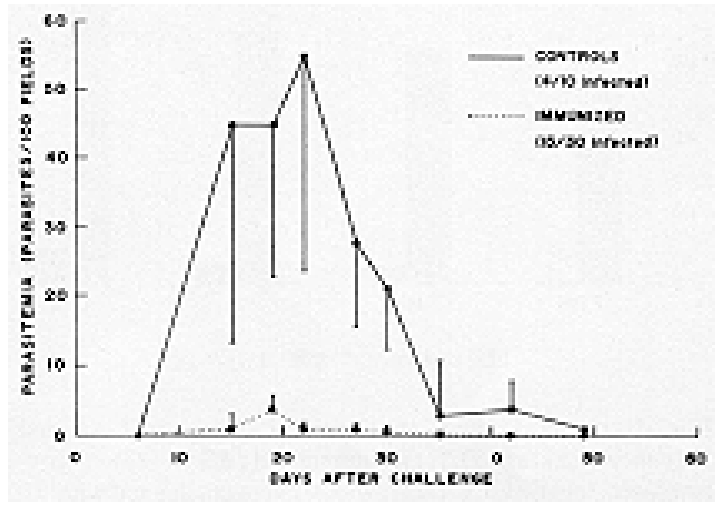

Fig. 1: infection rates and level of parasitemia in Swiss female mice challenged with 0.5 infective doses of Trypanosoma cruzi (10 trypomastigotes into the right hind footpad). Bars indicate the standard error.

Identification of infection-free animals after challenge at the site of delayed type hypersensitivity reaction - In order to induce an enhanced delayed type hypersensitivity reaction at the site of infection, experiments were performed in which a mixture of $10^{7}$ TCC and 10 virulent Tulahuen blood trypomastigotes was used as the challenge inoculum using mice primed as described above. The sensitized mice developed a strong and typical delayed type hypersensitivity reaction, evidenced by significant footpad swelling, which reached a maximum 18-24 $\mathrm{hr}$ post inoculation and disappeared after 3-4 days (Table II). Histologically, the swollen footpads showed edema and infiltration of lymphocytes and macrophages. The presence of systemic T. cruzi infection was studied with progressively sensitive methods in these animals: fresh blood mounts were carried out between day 10 and 30 after challenge. Microhematocrit, xenodiagnosis and hemoculture were performed before day 60. CML was studied after day 90. In most control animals, fresh bloods mounts were enough to detect infection. Search for circulating parasites with microhematocrit and xenodiagnosis in the control groups slightly increased the detection of infected animals, which was close to $100 \%$ and was not further increased by hemoculture and CML determinations. In contrast, a significant proportion (59\%) of immunized mice was completely resistant to infection in 
most experiments, as shown by negative, repeated parasitological results with all methods, including the absence of lytic antibodies 3-6 months after challenge (Fig. 2; Table II).

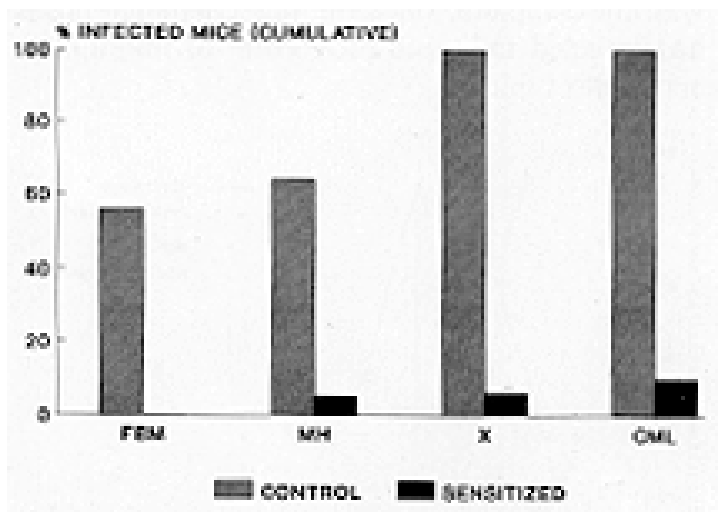

Fig. 2: immunization-challenge experiments against Trypanosoma cruzi. TCC pre-immunized ( $\quad, \mathrm{n}=28$ ) or control Swiss female mice $(, n=12)$ were challenged with 10 Tulahuen strain trypomastigotes admixed to $10^{7}$ TCC epimastigotes. All immunized mice developed strong delayed type hypersensitivity reactions at the site of infection (not shown). Infection was diagnosed with methods of progressive sensitivity: Fresh Blood Mount (FBM), Microhematocrit (MH), Xenodiagnosis (X) and Complement-Mediated Lysis (CML).
To further demonstrate the role of locally enhanced delayed type hypersensitivity reaction in the induction of total resistance, mice were challenged with virulent trypomastigotes, mixed or not with delayed type hypersensitivity inducing TCC epimastigotes (Fig. 3). This procedure showed that when a low number of infective parasites was injected alone, the use of progressively sensitive diagnostic methods revealed systemic infection in all control or preimmunized mice. In contrast, when the infective parasites were mixed with $10^{7}$ attenuated parasites and a strong delayed type hypersensitivity reaction occurred at the site of challenge, a significant proportion (40\%) of preimmunized mice, as compared to non immunized controls, remained completely free of virulent infection, as demonstrated by all methods, including absence of lytic antibodies.

Selection of naturally resistant mice showing complete immunization against vector-borne $\mathrm{T}$. cruzi - Eighteen, 4 month old mice received three immunizing subcutaneous inocula of $2 \times 10^{6} \mathrm{TCC}$ at weekly intervals. A week later they were challenged, together with 20 naive controls with 25 vector-borne, wild T. cruzi metacyclic trypomastigotes in the right hind footpad. Two determina-

TABLE II

Selection of mice with complete immunity to a low Trypanosoma cruzi challenge by enhancing DTH reactions at the site of infection ${ }^{a}$

\begin{tabular}{|c|c|c|c|c|c|c|c|c|c|}
\hline \multirow[b]{2}{*}{$\begin{array}{l}\text { Exp. } \\
\text { No. }\end{array}$} & \multirow[b]{2}{*}{ Sex } & \multirow[b]{2}{*}{ Group } & \multirow[b]{2}{*}{$\mathrm{DTH}^{b}$} & \multicolumn{5}{|c|}{$\begin{array}{l}\text { Cumulated number of mice with } \\
\text { positive diagnosis } / \text { total mice }\end{array}$} & \multirow{2}{*}{$\begin{array}{l}\text { Infected/ } \\
\text { Total } \\
\text { (final } \\
\text { result) }\end{array}$} \\
\hline & & & & FBM & $\mathrm{MH}$ & $\mathrm{X}$ & $\mathrm{H}$ & CML & \\
\hline $\begin{array}{c}1 \\
\text { (pilot) }\end{array}$ & $\mathrm{F}$ & $\begin{array}{l}\mathrm{S} \\
\mathrm{C}\end{array}$ & $\begin{array}{l}1.44 \pm 0.021 * * * * / d \\
0.44 \pm 0.05\end{array}$ & $\begin{array}{l}2 / 5 \\
5 / 5\end{array}$ & $\begin{array}{c}2 / 5 \\
-\end{array}$ & $\begin{array}{c}2 / 5 \\
-\end{array}$ & - & $\begin{array}{l}- \\
-\end{array}$ & $\begin{array}{l}2 / 5 \\
5 / 5\end{array}$ \\
\hline 2 & $\mathrm{~F}$ & $\begin{array}{l}\mathrm{S} \\
\mathrm{C}\end{array}$ & $\begin{array}{l}1.24 \pm 0.07 * * * * \\
0.42 \pm 0.02\end{array}$ & $\begin{array}{l}17 / 20 \\
13 / 15\end{array}$ & $\begin{array}{l}17 / 20 \\
13 / 15\end{array}$ & $\begin{array}{l}17 / 20 \\
13 / 15\end{array}$ & $\begin{array}{l}17 / 20 \\
13 / 15\end{array}$ & $\begin{array}{l}17 / 20 \\
13 / 15\end{array}$ & $\begin{array}{l}17 / 20 \\
13 / 15\end{array}$ \\
\hline 3 & $\mathrm{~F}$ & $\begin{array}{l}\mathrm{S} \\
\mathrm{C}\end{array}$ & $\begin{array}{l}1.11 \pm 0.09 * * * * \\
0.27 \pm 0.04\end{array}$ & $\begin{array}{l}2 / 28 \\
7 / 11\end{array}$ & $\begin{array}{l}2 / 28 \\
9 / 11\end{array}$ & $\begin{array}{c}2 / 28 \\
11 / 11\end{array}$ & $\begin{array}{c}2 / 28 \\
-\end{array}$ & $\begin{array}{c}2 / 28 \\
-\end{array}$ & $\begin{array}{l}2 / 28 * * * * \\
11 / 11\end{array}$ \\
\hline 4 & M & $\begin{array}{l}\mathrm{S} \\
\mathrm{C}\end{array}$ & $\begin{array}{l}1.20 \pm 0.06 * * * * \\
0.46 \pm 0.04\end{array}$ & $\begin{array}{c}24 / 51 \\
9 / 10\end{array}$ & $\begin{array}{l}31 / 51 \\
10 / 10\end{array}$ & $\begin{array}{c}32 / 51 \\
-\end{array}$ & $\begin{array}{c}32 / 51 \\
-\end{array}$ & $\begin{array}{c}32 / 51 \\
-\end{array}$ & $\begin{array}{l}32 / 51 * * \\
10 / 10\end{array}$ \\
\hline 5 & $\mathrm{~F}$ & $\begin{array}{l}\mathrm{S} \\
\mathrm{C}\end{array}$ & $\begin{array}{l}1.40 \pm 0.08 * * * * \\
0.18 \pm 0.02\end{array}$ & $\begin{array}{c}7 / 19 \\
20 / 20\end{array}$ & $\begin{array}{l}- \\
-\end{array}$ & $\begin{array}{c}12 / 19 \\
-\end{array}$ & $\begin{array}{c}12 / 19 \\
-\end{array}$ & $\begin{array}{c}12 / 19 \\
-\end{array}$ & $\begin{array}{l}12 / 19 * * * \\
20 / 20\end{array}$ \\
\hline 6 & $\mathrm{~F}$ & $\begin{array}{l}\mathrm{S} \\
\mathrm{C}\end{array}$ & $\begin{array}{l}1.46 \pm 0.05 * * * * \\
0.30 \pm 0.05\end{array}$ & $\begin{array}{c}10 / 45 \\
5 / 5\end{array}$ & - & $\begin{array}{c}12 / 45 \\
-\end{array}$ & $\begin{array}{c}12 / 45 \\
-\end{array}$ & $\begin{array}{c}13 / 45 \\
-\end{array}$ & $\begin{array}{l}13 / 45^{* * *} \\
5 / 5\end{array}$ \\
\hline
\end{tabular}

$a$ : mice were immunized with $10^{7} \mathrm{TCC}$ in the left hind footpad. One week later, immunized and control animals were challenged with 10 blood trypomastigotes of Tulahuen strain (except in experiment No. 5, which was challenged with 150 vector-borne metacyclic trypomastigotes), mixed in $30 \mu$ saline with $10^{7}$ TCC into the right hind footpad. $b$ : DTH = delayed-type hypersensitivity. Footpad swelling $(\mathrm{mm}) 24 \mathrm{hr}$ after inoculation, mean \pm standard error. $c$ : mice recorded as positive in a given column include those recorded as positive in previous columns. Abreviations: Exp.= experiment; $\mathrm{S}=$ sensitized; $\mathrm{C}=$ control; $\mathrm{FBM}=$ fresh blood $\mathrm{mount} ; \mathrm{MH}=$ microhematocrit; $\mathrm{X}=$ xenodiagnosis; $\mathrm{H}=$ hemoculture; $\mathrm{CML}=$ complement mediated lysis. $d:{ }^{*} \mathrm{p}<0.09 ; * * \mathrm{p}<0.05$; $* * * \mathrm{p}<0.01 ; * * * * \mathrm{p}<0.001$. 


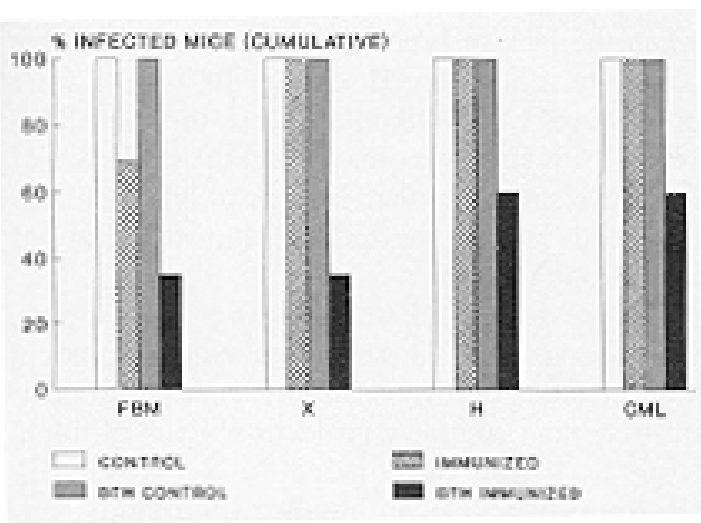

Fig. 3: immunization-challenge experiments against Trypanosoma cruzi. Infection of Swiss female mice by 150 insect-borne, wild $T$. cruzi metacyclic trypomastigotes in control $(\quad, n=5)$ or TCCpreimmunized (, $\mathrm{n}=20)$ Swiss male mice. In parallel, simultaneous group of mice, the challenge inoculum was admixed with $10^{7}$ epimastigotes and a strong delayed type hypersensitivity reaction (not shown) developed at the site of infection. This modality of challenge infected all control mice $(, n=20)$ but was totally resisted $(\mathrm{p}=0.002)$ by $40 \%$ of immunized mice ( , $\mathrm{n}=20$ ). Systemic infection was studied sequentially by Fresh Blood Mounts (FBM), Xenodiagnosis (X), Hemoculture (H) and Complement Mediated Lysis (CML).

tions (fresh blood mounts, studied on day 15 and microhematocrit on day 17 p.i.), showed infection in all controls and in 3/18 immunized mice. Between days 21 and 42 p.i., the remaining, apparently not infected mice of the immunized group were subjected to parasitemia determinations in three additional fresh blood mounts, one microhematocrit, hemoculture and xenodiagnosis with 30 nymphs per mouse. CML tests were performed after day 90 . As a result of these studies $T$. cruzi infection was demonstrated in seven additional immunized mice (Table III), but eight of these animals $(42 \%)$ remained free of detectable infection $(\mathrm{p}=0.00089)$.

\section{DISCUSSION}

Acquired immunological resistance against protozoan parasites is seldom complete, either in natural or in experimental infections (Andersen
1994). Previous failure to demonstrate sterile or complete immunity to $T$. cruzi challenge (McHardy \& Elphick 1980, reviewed in Kierszenbaum 1989, Basombrío et al. 1989) were connected with the capacity of this parasite to establish very low levels of infection and with the low sensitivity of the detection methods. We have attempted to surmount this problem by using the CML technique. The study of lytic antibodies seems to be the most convincing approach to address the demonstration of absence of infection by T. cruzi (Krettli \& Brener 1982), when the infecting strains or isolates are good inducers of this type of antibody. Such is the case with the Tulahuen and wild isolates used in this work. On the other hand, the TCC organisms we used for immunization do not appear to be good inducers of lytic antibodies, even in parasitologically proven infections (unpublished observations). Therefore, our procedure does not demonstrate sterile immunity in the immunized animals, but it does establish a complete, acquired resistance, at the skin level, against the virulent parasites used for challenge, in a significant number of animals.

When TCC-immunized and control mice were challenged with threshold doses of infecting parasites, the levels of parasitemia were sharply lower in the immunized group, although the proportion of infected mice was comparable in both groups. This indicates that the effects of immunization "are expressed at a stage of infection later than invasion", confirming the original notion of Mc Hardy and Elphick (1980). This led us to further concentrate efforts in the demonstration of complete resistance using two approaches: enhancing the delayed type hypersensitivity reaction at the subcutaneous level and testing the effects of immunization in animals in which natural resistance to $T$. cruzi was already strong. In the first approach, the $10^{7}: 10$ mixture of attenuated and virulent parasites induced a typical delayed type hypersensitivity reaction. This reaction was never seen, at least macroscopically, in mice challenged with virulent parasites alone. The failure of several parasitologic methods to detect systemic

\section{TABLE III}

Proportion of aged Swiss male mice, displaying complete immunization against Trypanosoma cruzi

\begin{tabular}{|c|c|c|c|c|c|c|}
\hline \multirow[b]{2}{*}{ Group } & \multicolumn{5}{|c|}{$\begin{array}{c}\text { Cumulated number of mice with } \\
\text { positive diagnosis/total mice }\end{array}$} & \multirow{2}{*}{$\begin{array}{c}\text { Infected/ } \\
\text { Total } \\
\text { (final } \\
\text { result) }^{a}\end{array}$} \\
\hline & $\begin{array}{l}\text { Fresh blood } \\
\text { mount }\end{array}$ & $\begin{array}{c}\text { Micro- } \\
\text { hematocrit }\end{array}$ & $\begin{array}{l}\text { Xeno- } \\
\text { diagnosis }\end{array}$ & $\begin{array}{l}\text { Hemo- } \\
\text { culture }\end{array}$ & CML & \\
\hline Immunized & $3 / 18$ & $7 / 18$ & $10 / 18$ & $10 / 18$ & $10 / 18$ & $10 / 18$ \\
\hline Control & $17 / 20$ & $20 / 20$ & - & - & - & $20 / 20$ \\
\hline
\end{tabular}

$a$ : statistic significance for rates of infection was evaluated with Fisher's exact test $(\mathrm{p}=0.00089)$ 
infection plus the absence of lytic antibodies in a significant proportion of immunized-challenged animals suggested that the infecting parasites were in such cases totally eliminated at the site of infection. This modality of challenge does not reflect the normal conditions of vectorial infection by $T$. cruzi and would thus not constitute a model of vaccination applicable to conditions of natural infection. In the second approach, which seems more relevant to natural T. cruzi infection, we tested the combined effects of natural and acquired resistance against vector-borne parasites. Four-month-old Swiss mice are at a time of their life when natural resistance to $T$. cruzi is highest (Basombrío \& Arredes 1987). Using these animals, we could demonstrate that low doses of vector borne, wild $T$. cruzi injected at the footpad, and which were $100 \%$ infective for control animals of the same age and sex, were completely eliminated at the site of infection in a significant proportion of immunized mice.

A survey of 66 published studies on experimental immunization against $T$. cruzi, involving various animals and immunogens concluded that complete immunological protection against this parasite had never been demonstrated (Kierszenbaum 1989). In most studies, immunized animals were challenged with large infective inocula and the ensuing parasitemias were measured with methods which not always detected very low levels of parasites. Such type of infections contrast with natural parasitism by $T$. cruzi, which results from low numbers of vector-borne parasites penetrating epithelia and which require more sensitive methods for detection. Only 14 of the 66 studies included methods of higher sensitivity than fresh blood mount (e.g., xenodiagnosis, hemoculture and sub-inoculation) and none of them used serological methods to exclude infection, as practiced by clinicians on patients (Galvão et al. 1993). Two of these studies deserve a special comment in this context, because both used the CML technique and, in one of them, parasitological results suggest total protection. Andrews et al. (1985) immunized A/Snell mice with three doses of 8-methoxypsoralen and U.V. light-treated, culture trypomastigotes and challenged them with blood trypomastigotes. While all control mice developed parasitemia and died, all immunized mice "survived with negative parasitemia (checked daily) and absence of tissue lesions". However, the immunized group presented lytic antibodies both before and after challenge, a result not consistent with absence of infection. Rodriguez et al. (1983) applied the CML technique to immunized-challenged rats 90 days after challenge, i.e., at a time when the lack of lytic antibodies would indicate complete protection. However, the results were positive for lytic antibodies. Thus, the overall results of this survey indicated that the exclusion of low levels of parasitism by lack of lytic antibodies had never revealed the success of immunoprotection.

In previous field studies using guinea pigs, we observed that a partial resistance, apparent with methods of low sensitivity, is easier to demonstrate than complete protection. Lack of infection was not demonstrated serologically (Basombrío 1990). In another field study performed in dogs (Basombrío et al. 1993) the exclusion of infected animals proceeded a step further by including serological data.

Identification of infected mice by CML showed in this work to be a useful and sensitive diagnostic method, since more advanced procedures, such as Polimerase Chain Reaction, are not yet available in all laboratories.

These results evidence that a significant number of immunized mice can totally reject an otherwise infectious $T$. cruzi challenge. They can not be attributed to the use of TCC parasites as immunogen, since these most often elicit a partial resistance. Total resistance at the skin level is a part, perhaps minor, among other, more apparent, components of immunity to T. cruzi. Its demonstration in individual animals seemed in this study to be associated with a particular set of experimental conditions, not often combined in previous experimental studies, such as threshold challenge, local delayed type hypersensitivity reaction and high natural host resistance. This set of experimental conditions, however particular, is by no means irrelevant to the usual way of transmission of $T$. cruzi from its insect vector to its reservoirs, including the human host.

\section{ACKNOWLEDGMENTS}

To Dr Sylvio C Gonçalves da Costa for teaching us delayed type hypersensitivity procedures. To Delfor Alejandro Uncos and Federico Ramos for their excellent technical support.

\section{REFERENCES}

Andersen RM 1994. Mathematical studies of parasite infection and immunity. Science 264: 1884-1886.

Andrews NW, Alves MJM, Schumacher RI, Colli W 1985. Trypanosoma cruzi: Protection in mice immunized with 8-Methoxypsoralen inactivated trypomastigotes. Experim Parasitol 60: 255-262.

Basombrío MA 1990. Trypanosoma cruzi: partial prevention of the natural infection of guinea pigs with a killed parasite vaccine. Exp Parasitol 71: 1-8.

Basombrío MA, Arredes H 1987. Long term immunological response induced by attenuated Trypano- 
soma cruzi in mice. J Parasitol 73: 236-238.

Basombrío MA, Arredes H, Uncos DA, Rossi R, Alvarez E 1987. Field trial of vaccination against American Trypanosomiasis (Chagas disease) in domestic guinea pigs. Am J Trop Med Hyg 37: 5762.

Basombrío MA, Besuschio S, Cossio P 1982. Side effects of immunization with live attenuated Trypanosoma cruzi in mice and rabbits. Infect Immun 36: 342-350.

Basombrío MA, Mora MC, Segura MA 1989. Protección inmunológica contra la enfermedad de Chagas. Efectos independientes sobre infección, diseminación y lesiones por Trypanosoma cruzi. Medicina (Buenos Aires) 49: 191-196.

Basombrío MA, Segura MA, Mora MC, Gómez L 1993. Field trial of vaccination against American Trypanosomiasis (Chagas disease) in dogs. Am J Trop Med Hyg 49: 143-151.

Brener Z, Plessman Camargo E 1982. Perspectives of vaccination in Chagas disease. Pontif Acad Sci (Scripta Varia) 47: 145-168.

Bua J, Bontempi E, Levin M, Orn A, Velasco D, Moreno M, Levi-Yeyati P, Engstrom A, Segura E, Ruiz A 1991. Trypanosoma cruzi: cellular and antibody response against the parasite in mice immunized with a 19-amino acid synthetic peptide. Exp Parasitol 72: 54-62.

Galvão LMC, Nunes RMB, Cançado JR, Brener Z, Krettli AU 1993. Lytic antibody titre as a means of assessing cure after treatment of Chagas dis- ease: a 10 years follow up study. Trans $R$ Soc Trop Med Hyg 87: 220-223.

Kierszenbaum F 1989. Chagas' disease, p.173-195. In FY Liew. Vaccination strategies of tropical diseases. CRC Press, Inc., Boca Raton, Florida.

Krettli A, Brener Z 1976. Protective effects of specific antibodies in Trypanosoma cruzi infections. $J$ Immunol 116: 755-760.

Krettli AU, Brener Z 1982. Resistance against Trypanosoma cruzi associated to anti-living trypomastigote antibodies. J Immunol 128: 20092012.

Krettli AU, Cançado JR, Brener Z 1982. Effect of specific chemotherapy on the levels of lytic antibodies in Chagas disease. Trans $R$ Soc Trop Med Hyg 76: $334-340$

McHardy N, Elphick JP 1980. Persistence of parasitaemia in vaccinated mice challenged with very low numbers of Trypanosoma cruzi. Trans $R$ Soc Trop Med Hyg 74: 670-671.

Murfin DJ, Kuhn RE 1988. Relative resistance of Brazil strain trypomastigote forms of Trypanosoma cruzi to in vitro antibody-dependent complement-mediated lysis. J Parasitol 74: 1046-1050.

Rodriguez AM, Afchain D, Rivera-Vandepras MT, Bazin H, Capron A 1983. Inmunoprotección de ratas por epimastigotes cultivados de Trypanosoma cruzi. Medicina (Buenos Aires) 43: 383-390.

WHO 1991. Control of Chagas Disease. Report of a WHO Expert Committe. World Health Organization, Technical Report Series 811. Geneva p. 47. 
